\title{
The gnu mutation of Drosophila causes inappropriate DNA synthesis in unfertilized and fertilized eggs
}

\author{
Matthew Freeman' ${ }^{1}$ and David M. Glover \\ Cancer Research Campaign, Eukaryotic Molecular Genetics Research Group, Department of Biochemistry, Imperial College \\ of Science and Technology, London SW7 2AZ, UK
}

\begin{abstract}
Drosophila melanogaster embryos whose mothers are homozygous for the maternal effect lethal mutation gnu (GNU embryos) undergo DNA synthesis but no nuclear division; this leads to the formation of a small number of giant nuclei in the syncytial blastoderm. We have shown previously that many components of the mitotic apparatus are present and functional in GNU embryos, and the primary lesion of the gnu mutation has therefore remained obscure. Here, we report that fertilization is not necessary for GNU eggs to develop. Giant nuclei originate from the products of female meiosis, and we see autonomously replicating centrosomes that must be maternally derived. If GNU eggs are inseminated, however, the male pronucleus also undergoes DNA replication. Our observations suggest that the GNU cytoplasm permits DNA synthesis in a relatively unregulated manner. In embryos from females homozygous for gnu and the female sterile haploid mutation $m h$, we find replication of DNA derived from the male pronucleus. This contrasts with embryos from mothers homozygous for $m h$ alone, in which this does not occur. We propose that the gnu gene product participates in the repression of DNA synthesis found in unfertilized eggs.
\end{abstract}

[Key Words: Drosophila; DNA replication; egg activation]

Little is known about the processes that regulate the activation of DNA synthesis and the subsequent onset of the mitotic cycle in fertilized eggs. Although extensive biochemical study, mainly of amphibian eggs, has demonstrated the involvement of several factors, such as maturation-promoting factor (MPF) (Wu anad Gerhart 1980, Miake-Lye et al. 1983), the molecular basis for this ubiquitous developmental switch is still unclear. The earliest stages of embryogenesis are easily observed in Drosophila eggs, and, coupled with the sophisticated genetic and molecular techniques available, this makes Drosophila an attractive organism with which to study these events. In this report we demonstrate that gnu gene product of Drosophila is involved in the repression of DNA replication that occurs in unfertilized eggs.

gnu is a maternal effect lethal mutation of Drosophila melanogaster, which maps on the third chromosome at 42.5 map units. It has the striking phenotype that embryos whose mothers are homozygous for the mutation (GNU embryos) undergo DNA synthesis but no nuclear division. This leads to the formation of a syncytial blastoderm that contains a small number of giant nuclei instead of the normal rapidly dividing diploid nuclei seen in wild-type embryos; GNU embryos never cellularize (Freeman et al. 1986). This phenotype led us to believe that the product of the gnu gene participates in the mi-

1Present address: Department of Biochemistry, University of California, Berkeley, California 94720 USA. totic division cycle during embryogenesis. However, we have shown previously that many of the components of the mitotic apparatus in GNU embryos are present and functionally adequate (Freeman et al. 1986), and the primary lesion of the gnu mutation therefore remained obscure.

Here, we report the unexpected observation that GNU eggs develop even if unfertilized, to give giant nuclei that originate solely from the products of female meiosis. We have also examined the replication of the parental genomes in GNU eggs, and on the basis of these results, we propose that the gnu gene product plays a part in the mechanism that normally represses DNA synthesis in the unfertilized egg. In addition, we have exploited the development of uninseminated GNU eggs to show that there is no requirement for a paternal contribution for the formation of centrosomes in the Drosophila embryo.

\section{Results}

\section{Abnormal DNA synthesis in GNU eggs}

Unfertilized wild-type Drosophila eggs are arrested at the end of meiosis II (Doane 1960), so that the four haploid products of female meiosis - the three polar bodies and the pronucleus - are present and can be observed in fixed eggs stained with a DNA-binding fluorochrome, as seen in Figure 1a. An unreplicated nucleus, one of the 
products of female meiosis, is indicated with an arrow, and the inset panel shows a similar nucleus at a higher magnification. The state of the chromatin in these eggs

a

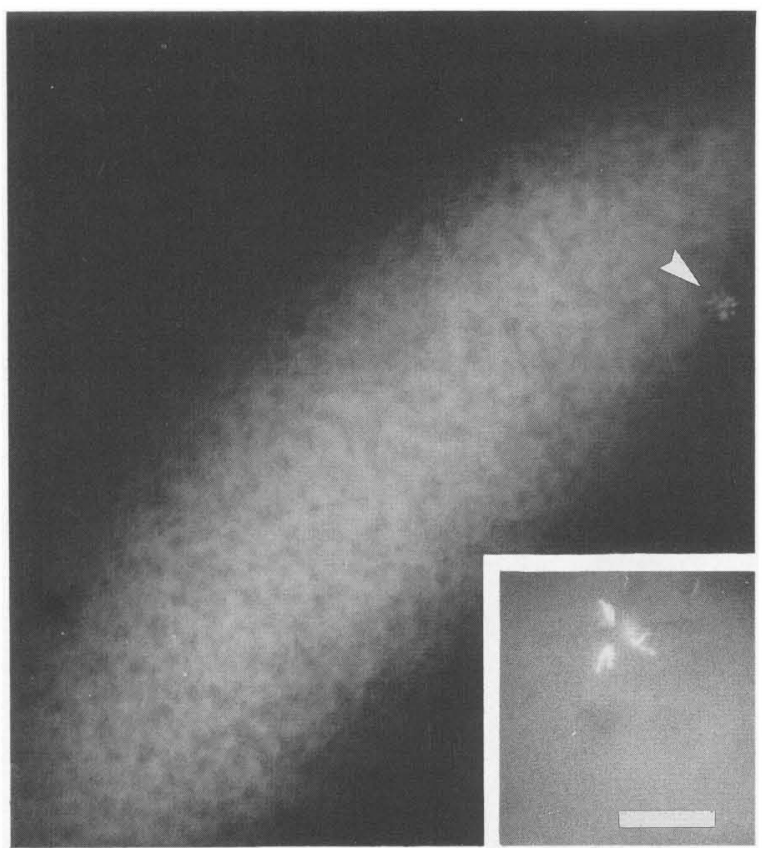

b

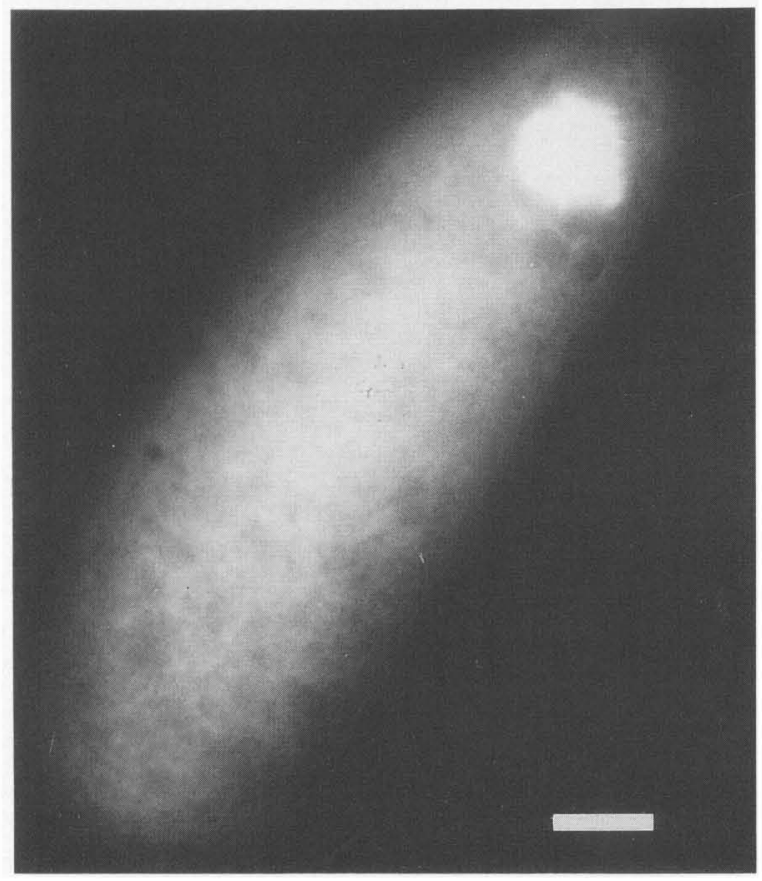

Figure 1. The nuclei of unfertilized Drosophila eggs from wild-type $(a)$ and homozgyous $(b)$ gnu mothers. Eggs laid overnight at $24^{\circ} \mathrm{C}$ by virgin females were fixed and stained with the DNA intercalating dye, Hoechst 33258. (a) Wild-type egg in which there is no sign of development. The arrow points to condensed chromatin from the polar bodies, and the inset panel shows a similar structure at a higher magnification (bar represents $10 \mu \mathrm{m}) .(b)$ An unfertilized GNU egg. In contrast to the wild-type egg, considerable DNA replication has occurred, leading to the formation of a giant nucleus. We can see no cytological difference between fertilized and unfertilized GNU eggs. Bar represents $50 \mu \mathrm{m}$. varies: In some cases (as in Fig. la), the chromosomes are highly condensed, and in other eggs, they are condensed and diffuse. Two or more of the meiotic products often fuse, so that what is usually observed in practice is between one and four separate nuclei. Eggs laid by virgin females homozygous for gnu are strikingly different (Fig. 1b). Instead of being developmentally arrested, the female meiotic products undergo DNA synthesis, and the eggs develop giant nuclei; these eggs are cytologically indistinguishable from GNU eggs laid by females that have been allowed to mate with males. This result suggests that the gnu mutations lifts the total block to DNA replication that exists in the wild-type unfertilized egg.

The gnu mutation also affects the development of the polar bodies, the three haploid products of female meiosis other than the female pronucleus. In the wildtype fertilized egg, the three polar bodies are not destined to participate in further development and show no sign of replication, even though they persist throughout cleavage (Rabinowitz 1941). In contrast, when we examine GNU embryos soon after oviposition, we frequently see that the polar bodies have undergone replication (data not shown), giving rise to giant nuclei in older embryos.

\section{Centrosomes are present in unfertilized GNU eggs}

Centrosomes are the organelles that organize the poles of the mitotic spindles. We have observed previously that centrosomes replicate independently of nuclei in fertilized GNU embryos and that they are capable of nucleating microtubules into asters, although spindles per se are not formed (Freeman et al. 1986). The parent that donates the centrosomes needed in embryogenesis varies between species (Schatten et al. 1986). Thus, the mouse embyro acquires centrosomes maternally, whereas the centrosomes in sea urchins are contributed by the incoming sperm. In Drosophila, the centrosomal source is unclear, although the centriole, the organelle normally found at the center of the centrosome, appears to be derived paternally (Sonnenblick 1950). We have exploited the development of uninseminated GNU eggs to discover whether a paternal contribution is necessary for centrosome formation in Drosophila. The monoclonal antibody Bx63 (Frasch et al. 1986), which recognizes a Drosophila centrosome-associated antigen, has been used to label uninseminated GNU eggs by indirect immunofluorescence. Figure 2 shows that centrosomes are found in these eggs, and that these are able to nucleate microtubules into asters that are similar to those seen previously in fertilized GNU eggs (Freeman et al. 1986). This indicates that there is not an absolute requirement for a male contribution to the formation of the centrosomes used during cleavage in Drosophila.

\section{Sperm pronuclei can undergo DNA synthesis in GNU eggs}

A question that arises from the observation that GNU eggs can develop even in unfertilized is whether the eggs 

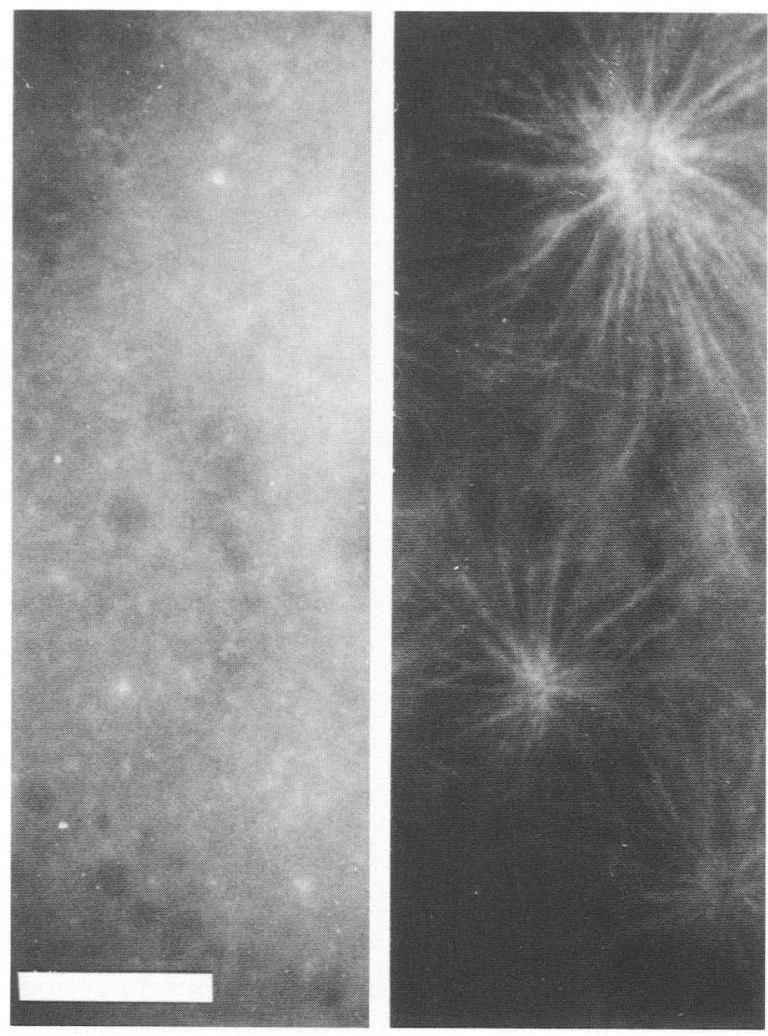

Figure 2. Unfertilized GNU eggs contain centrosomes and asters. Eggs from virgin gnu/gnu females were collected overnight at $24^{\circ} \mathrm{C}$ and stained by indirect immunofluorescence, using the mouse monoclonal antibody Bx63 against Drosophila centrosomes and the rat monoclonal antibody YL1/2 against tubulin. The centrosome (left) and tubulin (right) staining in one of the eggs is shown. Three centrosomes can be seen in the field, and each lies at the center of a microtubule aster. This result indicates clearly that the unfertilized Drosophila egg has the capacity to form functional centrosomes without any contribution from the sperm.

are capable of being inseminated and, if so, whether DNA of the sperm pronucleus is then replicated. To address this question, homozygous gnu females were mated with males of a transformed strain whose DNA was marked with a bacterial chloramphenicol acetyltransferase (CAT) gene (Gorman et al. 1982). DNA was prepared from embryos collected from this cross and hybridized with radiolabeled probes for the larval serum protein (LSP) 1 $\alpha$ gene, present in DNA from both males and females, or the CAT gene, present only in DNA from the males. This has allowed us to determine unambiguously whether DNA of the male pronucleus replicates in GNU embryos. Figure 3a confirms that the CAT probe does not detect DNA sequences in wild-type or GNU embryos fertilized by males not carrying the CAT gene. Figure $3 \mathrm{~b}$ shows that when wild-type females are mated with males bearing the CAT gene, the paternal genome replicates as expected (Fig. $3 \mathrm{~b}$ ). In this case, half the DNA in the developing embyro is derived from the male pronucleus, and similar hybridization signals can be seen with the LSP and CAT probes. An equivalent signal is also seen with LSP and CAT probes when homozygous gnu females are mated with CAT-bearing males (Fig. 3b), indicating that the male pronucleus does replicate in GNU eggs. This indicates that although GNU eggs can develop when unfertilized, they can also be inseminated, and when they are, the sperm pronucleus undergoes DNA synthesis, participating in the formation of giant nuclei.

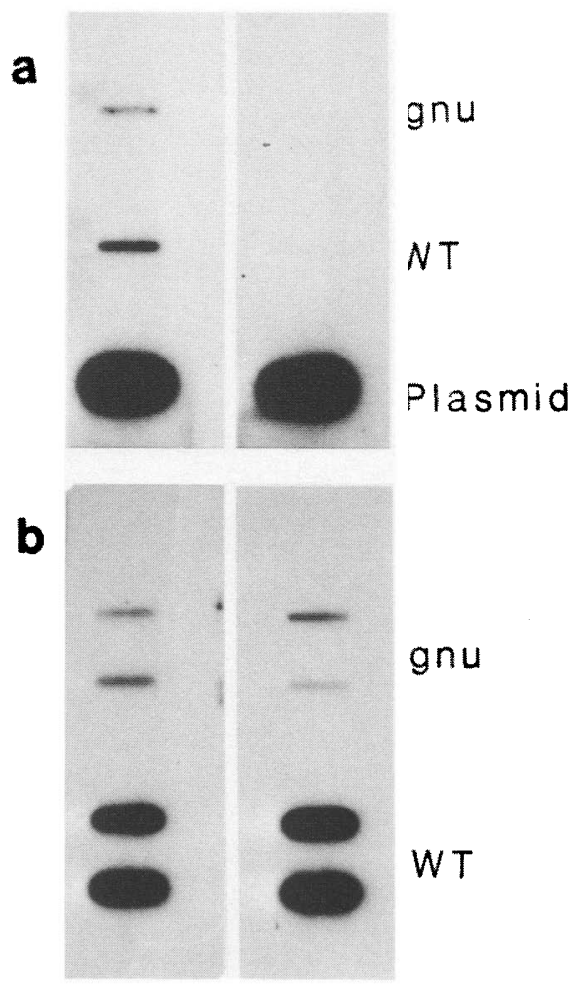

Figure 3. The male pronucleus replicates in inseminated GNU eggs. (a) DNA was isolated from embryos from a cross between wild-type (WT) or gnu/gnu (gnu) females and males not carrying the CAT gene. The DNA from 250 embryos was divided into two equal parts and probed with a radiolabeled DNA probe containing a 1.6-kb fragment of the Drosophila LSP $1 \alpha$ gene (left panel) or a similarly sized fragment of the CAT gene (right panel). There is no hybridization of DNA of either type of embryo with the CAT probe, demonstrating the absence of CAT sequences in the genome of wild-type or GNU embryos. The LSP hybridization signal is higher in wild-type than in GNU embryos, indicating that although giant nuclei are formed, the GNU embryos do not replicate their DNA to the same extent as fully developed wild-type embryos do. The plasmid control is $5 \mathrm{ng}$ of the parental plasmid from which each probe was isolated. The approximately equal degrees of hybridization of the LSP and CAT probes shows that both were of equivalent specific activity. (b) DNA was isolated from embryos from a cross between males bearing the CAT gene and wild-type (WT) or gnu/gnu (gnu) females that have no CAT sequences in their genomes. The DNA from 200 embryos (upper band in each pair) and 300 embryos (lower band in each pair) was divided into two equal parts and probed with the LSP (left panel) and CAT (right panel) probes, as above. The CAT probe hybridizes with DNA from both types of embryo, indicating that DNA derived from the male is replicated in both wild-type embryos and GNU embryos. 
gnu causes the replication of male-derived DNA in embryos whose mothers are homozygous for a maternal haploid mutation

It seems that GNU cytoplasm permits indiscriminate DNA synthesis in all nuclei within the egg. We tested this idea further by combining the gnu mutation in the maternal genome with the X-linked female sterile haploid mutation $m h$ (Gans et al. 1975; Zalokar et al. 1975; Santamaria and Gans 1980). Cytological and genetic analysis of embryos from females homozygous for $\mathrm{mh}$ (referred to here as $\mathrm{MH}$ embryos) has shown that the male pronucleus enters the egg but does not participate in syngamy, and that the female pronucleus alone is the source of the haploid cleavage nuclei in $\mathrm{MH}$ embryos (Santamaria and Gans 1980; Santamaria 1983). We constructed females homozygous for both gnu and $\mathrm{mh}$ in order to test whether the male pronucleus, which is unable to develop in the cytoplasm of an $\mathrm{MH}$ embryo, will replicate its DNA when the gnu gene is also mutated. As in the previous experiment, these females were mated with males bearing the CAT gene, and DNA from the resulting embryos was hybridized with an LSP probe and a CAT probe. Figure 4 demonstrates that, as expected, the male genome is significantly underreplicated in embryos resulting from a cross between females homozygous for $m h$ alone and CAT-bearing males. However, when CAT-bearing males are mated to females homozygous for $m h$ and gnu, the resulting embryos, which resemble GNU embryos in phenotype (data not shown), replicate male-derived DNA to approximately the same extent as female-derived DNA (Fig. 4b). Figure 4 includes diagrams of the eggs derived from mothers of both genotypes, intended to clarify the main results of this experiment. The weak hybridization between the CAT probe and DNA from $\mathrm{MH}$ embryos from a cross with CAT-bearing males (Fig. 4a) is probably due to a small amount of aberrant replication of the male pronucleus in the developing $\mathrm{MH}$ egg. Previous experiments that have analyzed the $m$ h mutation have shown clearly that the male pronucleus does not participate in cleavage (Zalokar et al. 1975; Santamaria and Gans 1980; Santamaria 1983), but do not rule out some such replication. Nevertheless, the ratio of CAT : LSP hybridization is much greater in $\mathrm{MH}_{\text {; }} \mathrm{GNU}$ embryos than in those derived from females homozygous for $m h$ alone, indicating that the gnu mutation is overriding some block to male pronuclear replication. This provides a further example in which DNA from an embyro nucleus that would not normally replicate does so when the gnu gene is mutated.

\section{Discussion}

Our results suggest that the wild-type product of the gnu gene plays a part in the repression of DNA synthesis that is found in the unfertilized egg. Because a similar block occurs in nearly all sexually reproducing species, its mechanism is of general interest. We have found several separate examples of abnormal DNA synthesis occurring in GNU eggs. First, the DNA of the haploid nuclei derived from female meiosis undergoes replication in GNU eggs that have not been fertilized. Whether or not GNU eggs are fertilized, the three polar bodies, as well as the female pronucleus, undergo DNA synthesis, whereas the polar bodies do not replicate at all in wildtype eggs. Finally, the male pronuclear DNA undergoes replication in fertilized GNU eggs, thereby participating in the formation of giant nuclei. This occurs even when eggs are derived from mothers homozygous for both gnu and the female sterile haploid mutation $\mathrm{mh}$. In contrast,

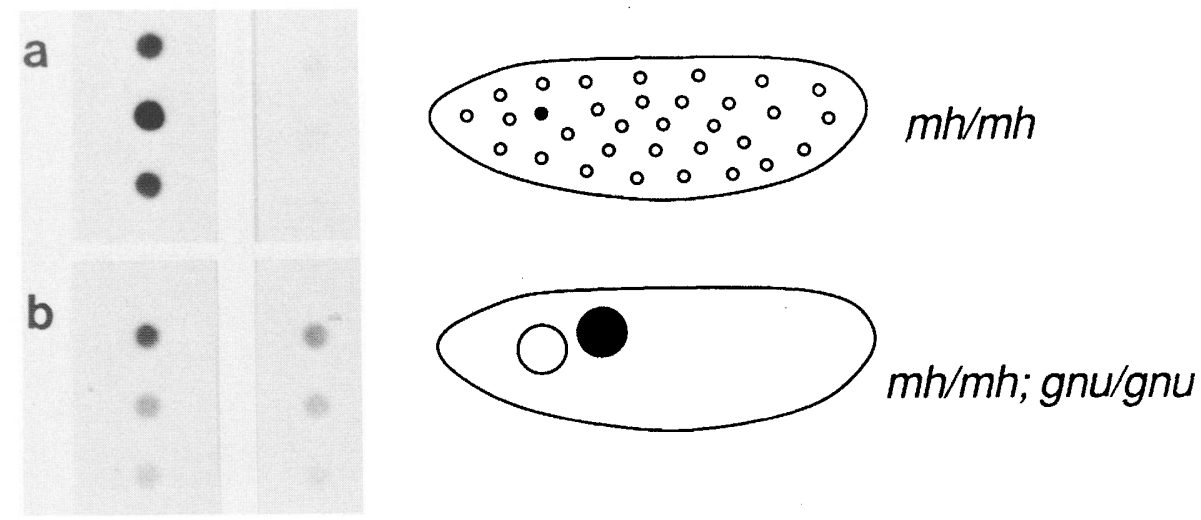

Figure 4. The male pronucleus does not replicate in $\mathrm{MH}$ embryos but does in MH;GNU embryos. (a) DNA was isolated from three batches of embryos (0-24 hr old) from a cross between $\mathrm{mh} / \mathrm{mh}$ females and males bearing the CAT gene 1400 , 400, and 300 embryos, from top to bottom). The DNA samples were divided into two equal parts and probed with the radiolabeled probes LSP (left panel) and CAT (right panel), described in the legend to Fig. 3. Only a small amount of hybridization is seen with the CAT gene, compared with the LSP gene, indicating that the male-derived DNA is considerably less replicated than female-derived DNA. A representation of an $\mathrm{MH}$ embryo during cleavage is shown; (O) haploid nuclei derived from the female pronucleus; (O) the male pronucleus. (b) DNA was isolated, as described above, from a cross between $\mathrm{mh} / \mathrm{mh}$;gnu/gnu females and males bearing the CAT gene (230, 160, and 160 embryos, from top to bottom). The DNA samples were divided into two equal parts and probed with LSP (left panel) and CAT (right panel). Equivalent amounts of hybridization are seen with both probes, indicating that male- derived DNA is significantly replicated. A representation of these $\mathrm{MH}$;GNU embryos is shown; (O) Female-derived giant nucleus; (O) male-derived giant nucleus. 
fertilized eggs derived from mothers homozygous for $\mathrm{mh}$ alone, in which the male pronucleus does not participate in syngamy (Zalokar et al. 1975; Santamaria and Gans 1980, Santamaria 1983), show no significant replication of male pronuclear DNA. These cases of inappropriate DNA synthesis suggest that the gnu mutation sets up a "replicative environment" in the GNU egg, in which relatively indiscriminate DNA synthesis can occur.

These results are consistent with a model in which DNA replication in the early embryo is normally only possible for a nucleus that has achieved syngamy. This would ensure that the nuclei in the unfertilized egg do not replicate prior to sperm entry and that the polar bodies do not undergo further development, even after fertilization. If gnu mutants are defective in a component of the system that is responsible for this repression, we would expect to find the pattern of DNA synthesis that is seen in GNU embryos. This uncontrolled DNA synthesis appears to prevent normal mitosis from being initiated, resulting in the formation of giant nuclei. The details of this model are obviously speculative, but there is good evidence that the gnu gene product plays a part in the repression of DNA synthesis in the Drosophila egg.

Uninseminated GNU eggs contain functional centrosomes, indicating that all the components needed for the formation of these organelles can be provided maternally. A similar result has been obtained in the artificially activated sea urchin egg (Dirksen 1961) which, as noted above, is a species that normally obtains a centrosome from the sperm. Thus, under certain conditions, at least two species that are generally accepted to have a paternal requirement for provision of a centrosome (Sonnenblick 1950; Schatten et al. 1986) can produce these organelles entirely from maternal products. This result does not rule out the possibility that there is normally a paternal contribution of centrosomes in wildtype development, but it does demonstrate that any such contribution is not essential. The result with GNU embryos is perhaps not surprising, as there are several Drosophila species that undergo significant rates of parthenogenesis (Templeton 1983), and a parthenogenetically derived embryo clearly must be derived entirely from maternal components. Although D. melanogaster does not normally show significant rates of parthenogenesis, a male sterile mutation, $\mathrm{ms}(3) \mathrm{K} 81$ (Fuyama 1984, 1986), has been isolated in which sperm from homozygous males can activate egg development but are unable to participate in syngamy. Some of these activated eggs undergo considerable development, even though all their cells are derived from the female pronucleus. Indeed, Fuyama has established a strain that reproduces gynogenetically when inseminated by $m s(3) K 81$ males (see discussion of Fuyama 1986), although the nature of the genetic variant in this strain is not yet clear. It is not known whether the centrosomes in these gynogenetic individuals are contributed maternally or by the mutant sperm. The interactions between mutants of this kind, gnu and $m h$, will allow us to begin to deduce a network of epistatic interactions between genes involved in the repression of DNA synthesis in, and the subsequent activation of, the unfertilized egg.

The molecular mechanisms of egg activation are poorly understood (Went 1982). Biochemical studies of amphibian eggs have led to the isolation of factors, such as MPF and cytostatic factor (CSF), that clearly play a part in the metaphase arrest of the unfertilized egg and the subsequent activation of DNA synthesis (Masui and Markert 1971; Smith and Ecker 1971; Meyerhof and Masui 1979; Maller and Krebs 1980; Wu and Gerhart 1980; Miake-Lye et al. 1983). MPF is of particular interest, as it is present in all cell types examined, and its level is found to cycle in unison with the mitotic cell cycle (Gerhart et al. 1984; Newport and Kirschner 1984); it is thus thought to be an important regulatory element of mitosis throughout development, rather than being confined to its role around the time of fertilization. However, the difficulty of purifying these factors means that their precise roles have remained elusive. The defects caused by the gnu mutation suggest that the wildtype gene product may participate in the equivalent processes of egg activation in the Drosophila egg. The molecular genetic analysis of the gnu gene that is now in progress should provide new insights into the mechanisms underlying the onset of DNA synthesis and the consequent initiation of development in the fertilized egg.

\section{Materials and methods}

\section{Drosophila stocks and egg collection}

Wild-type stocks were from cultures of Oregon- $R$ strain (Lindsley and Grell 1968), maintained continuously in this laboratory. The line of flies carrying the bacterial CAT gene was $\alpha \mathrm{T} 3.1$, as described by Davies et al. (1986). The mutation $m h$ was the gift of $M$. Gans, and has been described previously (Gans et al. 1975; Zalokar et al. 1975; Santamaria and Gans 1980|. All fly stocks were kept under standard culture conditions (Roberts 1986).

Embryos were collected on petri dishes containing grape juice agar ( $80 \mathrm{~g}$ sucrose, $8 \mathrm{~g}$ yeast, $48 \mathrm{ml}$ concentrated grape juice, 25 $\mathrm{g}$ agar per liter), supplemented with a yeast paste. These dishes were fitted to the bottoms of one-third pint milk bottles, with their bases removed.

\section{Antibodies}

We used the mouse monoclonal antibody Bx63 (Frasch et al. 1986) against Drosophila centrosomes and the rat monoclonal YL1/2 (Sera-Lab, UK) (Kilmartin et al. 1982) against tubulin. YL1/2 has been shown to recognize specifically $\alpha$-tubulin in Drosophila (Warn and Warn 1985). Dilutions of between 1 in 5 and 1 in 15 were used for hybridoma culture supernatant, and dilutions of 1 in 500 for ascites fluid, all in Buffer A [15 mM Tris- $\mathrm{HCl}$ ( $\mathrm{pH} 7.4$ ), $60 \mathrm{~mm} \mathrm{KCl}, 15 \mathrm{~mm} \mathrm{NaCl}, 1.5 \mathrm{~mm}$ spermine, $0.5 \mathrm{~mm}$ spermidine]. Rhodamine- and fluoroscein-conjugated second antibodies were bought from Jackson Immunoresearch Laboratories, Inc. (USA), and used at 1 in 500 and 1 in 100, respectively. 


\section{Embryo fixation and permeabilization}

Embryos were fixed and prepared for staining by a technique that has been described previously (Freeman et al. 1986). The embryos were treated with $0.5 \mu \mathrm{M}$ taxol, a microtubule-stabilizing toxin, for $30 \mathrm{sec}$ prior to fixation. Under these conditions, taxol is believed not to cause aberrant polymerization of tubulin in Drosophila embryos (Karr and Alberts 1986; Freeman et al. 1986).

\section{Antibody staining of embryos}

Embryos were stained immunofluorescently and photographed as described previously (Freeman et al. 1986). Antibodies were applied in the order Bx63, goat anti-mouse $\operatorname{IgG}(\mathrm{H}+\mathrm{L}), \mathrm{YL} 1 / 2$, goat anti-rat $\operatorname{IgG}(\mathrm{H}+\mathrm{L})$.

\section{DNA preparation}

DNA was prepared by a modification of a protocol described previously (De Cicco and Glover 1983), using between 50 and 300 embryos in place of a single fly and increasing the volumes by $50 \%$. DNA preparations were treated with proteinase $\mathrm{K}$ (100 $\mu \mathrm{g} / \mathrm{ml} 45^{\circ} \mathrm{C}, 60 \mathrm{~min}$ ) and phenol-extracted, before being ethanol-precipitated and resuspended in TE $[10 \mathrm{mM}$ Tris- $\mathrm{HCl} / \mathrm{pH}$ 8.0), 1 mM EDTA].

\section{DNA hybridization probes}

The LSP plasmid used as a hybridization probe was a $1.65-\mathrm{kb}$ $B a m H I$ fragment from the 5' end of the Drosophila LSP $1 \alpha$ gene (Smith et al. 1981), cloned into pEMBL8(+) (Dente et al. 1983). The CAT plasmid was a 1.64-kb BamHI-BglII fragment of pSVOCAT (Gorman et al. 1982), which contains the Escherichia coli CAT gene, cloned into pEMBL9( + | (Dente et al. 1983).

\section{DNA blotting and hybridization}

DNA was immobilized onto nitrocellulose filters using a Schleicher \& Schull Slot Blot apparatus, and the manufacturer's instructions were followed. Hybridization was carried out under normal, high-stringency conditions (Maniatis et al. 1982), and the radiolabeled probes were prepared by the oligo-labeling method of Feinberg and Vogelstein $(1983,1984)$.

\section{Acknowledgments}

We are grateful to S. Millar and S. Cotterill for their helpful comments on the manuscript. This work was supported by the Cancer Research Campaign. M.F. acknowledges an MRC Research Studentship.

\section{References}

Davies, J.A., C.F. Addison, S.J. Delaney, C. Sunkel, and D.M. Glover. 1986. Expression of the prokaryotic gene for chloramphenicol acetyltransferase in Drosophila under the control of the larval serum protein 1 gene promoters. $J$. Mol. Biol. 189: 13-24.

De Cicco, D.V. and D.M. Glover. 1983. Amplification of rDNA and type 1 sequences in Drosophila males deficient in rDNA. Cell 32: 1217-1225.

Dente, L., G. Cesareni, and R. Cortese. 1983. pEMBL: A new family of single stranded plasmids. Nucleic Acid Res. 11: $1645-1655$.

Dirksen, E.R. 1961. The presence of centrioles in artificially ac- tivated sea urchin eggs. J. Biophys. Biochem. Cytol. 11: $244-247$.

Doane, W.W. 1960. Completion of meiosis in uninseminated eggs of Drosophila melanogaster. Science 132: 677-678.

Feinberg, A.P. and B. Vogelstein. 1983. A technique for radiolabelling DNA restriction endonuclease fragments to high specific activity. Anal. Biochem. 132: 6-13.

. 1984. Addendum. Anal. Biochem. 137: 266-267.

Frasch, M., D.M. Glover, and H. Saumweber. 1986. Nuclear antigens follow different pathways into daughter nuclei during mitosis in early Drosophila embryos. J. Cell Sci. 82: 155172.

Freeman, M., C. Nüsslein-Volhard, and D.M. Glover. 1986. The dissociation of nuclear and centrosomal division in $g n u$, a mutation causing giant nuclei in Drosophila. Cell 46: 457468.

Fuyama, Y. 1984. Gynogenesis in Drosophila melanogaster. Ipn. I. Genet. 59: 91-96.

- 1986. Genetics of parthenogenesis in Drosophila melanogaster. I. The modes of diploidisation in the gynogenesis induced by a male sterile mutant, $\mathrm{ms}(3) \mathrm{K} 81$. Genetics 112: 237-248.

Gans, M., C. Audit, and M. Masson. 1975. The isolation and characterisation of sex-linked female sterile mutants in Drosophila melanogaster. Genetics 81: 683-704.

Gerhart, J., M. Wu, and M. Kirschner. 1984. Cell cycle dynamics of an $M$ - phase-specific cytoplasmic factor in Xenopus laevis oocytes and eggs. I. Cell Biol. 98: 12471255.

Gorman, C.M., L.F. Moffat, and B.H. Howard. 1982. Recombinant genomes which express chloramphenicol acetyltransferase in mammalian cells. Mol. Cell. Biol. 2: 1044-1051.

Karr, T.L. and B.M. Alberts. 1986. Organisation of the cytoskeleton in early Drosophila embryos. J. Cell Biol. 102: 14941509.

Kilmartin, J.V., B. Wright, and C. Milstein. 1982. Rat monoclonal antitubulin antibodies derived using a new nonsecreting rat cell line. J. Cell Biol. 93: 576-582.

Lindsley, D.L. and E.H. Grell. 1968. Genetic variations of Drosophila. Carnegie Institute of Washington. Publ. No. 627.

Maller, J.L. and E.G. Krebs. 1980. Regulation of oocyte maturation. Curr. Top. Cell. Reg. 16: 271-311.

Maniatis, T., E.F. Fritsch, and J. Sambrook. 1982. Molecular cloning: A laboratory manual. Cold Spring Harbor Laboratory, Cold Spring Harbor, New York.

Masui, Y. and C.L. Markert. 1971. Cytoplasmic control of nuclear behaviour during meiotic maturation of frog oocytes. $J$. Exp. Zool. 177: 129-146.

Meyerhof, P.G. and Y. Masui. 1979. Properties of a cytostatic factor from Xenopus laevis eggs. Dev. Biol. 72: 182-187.

Miake-Lye, R., J. Newport, and M. Kirschner. 1983. Maturation-promoter factor induces nuclear envelope breakdown in cycloheximide-arrested embryos of Xenopus laevis. I. Cell Biol. 97: 81-91.

Newport, J.W. and M.W. Kirschner. 1984. Regulation of the cell cycle during early Xenopus development. Cell 37: 731-742.

Rabinowitz, M. 1941. Studies on the cytology and early embryology of the egg of Drosophila melanogaster. I. Morphol. 69: 1-49.

Roberts, D.B. 1986. Basic Drosophila care and techniques . In Drosophila: A practical approach (ed. D.B. Roberts), IRL Press, Oxford.

Santamaria, P. 1983. Analysis of haploid mosaics in Drosophila. Dev. Biol. 96: 285-295.

Santamaria, P. and M. Gans. 1980. Chimaeras of Drosophila melanogaster obtained by injection of haploid nuclei. $\mathrm{Na}$ ture 287: 143-144. 
Schatten, H., G. Schatten, D. Mazia, R. Balczon, and C. Simerly. 1986. Behaviour of centrosomes during fertilization and cell division in mouse oocytes and sea urchin eggs. Proc. Natl. Acad. Sci. 83: 105-109.

Smith, D.F., A. McClelland, B.N. White, C.F. Addison, and D.M. Glover. 1981. The molecular cloning of a dispersed set of developmentally regulated genes which encode the major larval serum protein of Drosophila melanogaster. Cell 23: $441-449$.

Smith, L.D. and R.E. Ecker. 1971. The interaction of steroids with Rana pipiens oocytes in the induction of maturation. Dev. Biol. 25: 232-247.

Sonnenblick, P.B. 1950. The early embryology of Drosophila melanogaster. In Biology of Drosophila (ed. M. Demerec), pp. 62-167. Wiley, New York.

Templeton, A.R. 1983. Natural and experimental parthenogenesis. In Genetics and biology of Drosophila, vol. 3C (ed. M. Ashburner, H.L. Carson, and J.N. Thompson), Academic Press, London.

Warn, R.M. and A. Warn. 1985. Microtubule arrays present during the syncytial blastoderm stage of the Drosophila embryo. Exp. Cell. Res. 163: 201-210.

Went, D.F. 1982. Egg activation and parthenogenetic reproduction in insects. Biol. Rev. 57: 319-344.

Wu, M. and J.C. Gerhart. 1980. Partial purification and characterisation of the maturation-promoting factor from eggs of Xenopus laevis. Dev. Biol. 79: 465-477.

Zalokar, M., C. Audit, and I. Erk. 1975. Developmental defects of female sterile mutants of Drosophila melanogaster. Dev. Biol. 47: 419-432. 


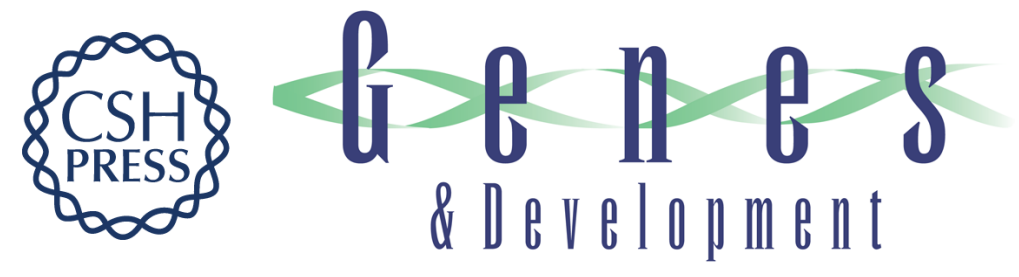

\section{The gnu mutation of Drosophila causes inappropriate DNA synthesis in unfertilized and fertilized eggs}

Genes Dev. 1987, 1:

Access the most recent version at doi:10.1101/gad.1.9.924

References This article cites 31 articles, 11 of which can be accessed free at:

http://genesdev.cshlp.org/content/1/9/924.full.html\#ref-list-1

License

Email Alerting Receive free email alerts when new articles cite this article - sign up in the box at the top Service right corner of the article or click here.

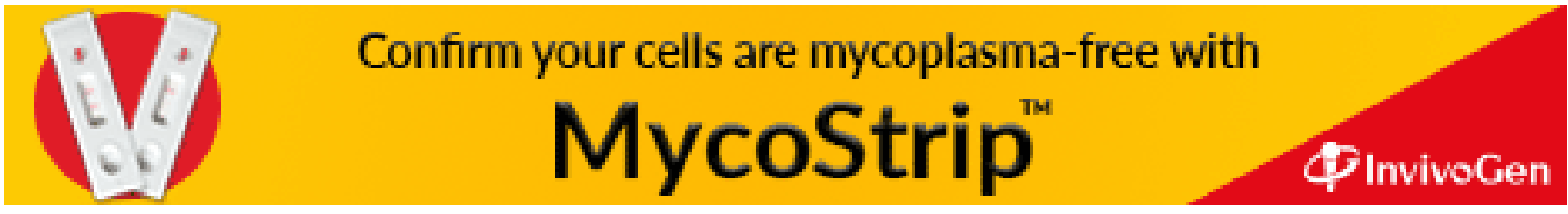

